(2)

\title{
Emerging role of PLAG1 as a regulator of growth and reproduction
}

\author{
Almas R Juma', Pauliina E Damdimopoulou ${ }^{2}$, Sylvia V H Grommen', \\ Wim J M Van de Ven ${ }^{3}$ and Bert De Groef ${ }^{1}$ \\ ${ }^{1}$ Department of Physiology, Anatomy and Microbiology, School of Life Sciences, La Trobe University, Bundoora, \\ Victoria 3086, Australia \\ ${ }^{2}$ Department of Clinical Sciences, Intervention and Technology, Karolinska Institutet and Karolinska University \\ Hospital, Huddinge, 14186 Stockholm, Sweden \\ ${ }^{3}$ Department of Human Genetics, KU Leuven, B-3000 Leuven, Belgium
}

\author{
Correspondence \\ should be addressed \\ to B De Groef \\ Email \\ b.degroef@latrobe.edu.au
}

\begin{abstract}
Pleomorphic adenoma gene 1 (PLAG1) belongs to the PLAG family of zinc finger transcription factors along with PLAG-like 1 and PLAG-like 2. The PLAG1 gene is best known as an oncogene associated with certain types of cancer, most notably pleomorphic adenomas of the salivary gland. While the mechanisms of PLAG1-induced tumorigenesis are reasonably well understood, the role of PLAG1 in normal physiology is less clear. It is known that PLAG1 is involved in cell proliferation by directly regulating a wide array of target genes, including a number of growth factors such as insulin-like growth factor 2 . This is likely to be a central mode of action for PLAG1 both in embryonic development and in cancer. The phenotype of Plag1 knockout mice suggests an important role for PLAG1 also in postnatal growth and reproduction, as PLAG1 deficiency causes growth retardation and reduced fertility. A role for PLAG1 in growth and reproduction is further corroborated by genome-wide association studies in humans and domestic animals in which polymorphisms in the PLAG1 genomic region are associated with body growth and reproductive traits. Here we review the current evidence for PLAG1 as a regulator of growth and fertility and discuss possible endocrine mechanisms involved.
\end{abstract}

\section{Key Words}

- pleomorphic adenoma gene 1

- zinc finger transcription factor

- growth

- reproduction

- puberty

- hypothalamo-pituitarygonadal axis

- insulin-like growth factors

\section{Introduction}

The transcription factor pleomorphic adenoma gene 1 (PLAG1) was first discovered via positional cloning when researchers were studying pleomorphic adenomas of the salivary glands (Kas et al. 1997). Its role in various types of cancer has been extensively studied since. Apart from salivary gland adenomas, PLAG1 was later shown to be involved in other human cancers such as lipoblastoma, hepatoblastoma, and acute myeloid leukemia (Åström et al. 2000, Zatkova et al. 2004, Landrette et al. 2005) and is also ectopically expressed in uterine leiomyoma and leiomyosarcoma (Åström et al. 1999). One of the causes of PLAG1-induced cancers is a reciprocal chromosomal translocation event, leading to swapping of the PLAG1 promoter with that of ubiquitously expressed genes. In pleomorphic adenomas of the salivary glands, translocation partners include genes such as CTNNB1 (which encodes $\beta$-catenin), LIFR (encoding the leukemia inhibitory factor receptor) and the transcription elongation factor SII gene (Kas et al. 1997, Voz et al. 1998, Åström et al. 1999). The chromosomal breakpoints are located between

Published by Bioscientifica Ltd 
the upstream regulatory region and the coding region of both translocation partners, preserving the coding sequence and functionality of the translated proteins involved. Following promoter swapping, PLAG1 expression comes under the control of strong promoters, leading to overexpression or ectopic activation of PLAG1. This in turn results in a deregulation of PLAG1 target genes and tumor formation (Voz et al. 2000, 2004). The tumorigenic capacity of PLAG1 was confirmed in transgenic mouse models in which targeted Plag1 overexpression in the salivary and mammary glands resulted in tumor development (Declercq et al. 2005).

In contrast to our fairly detailed knowledge about the mechanisms behind PLAG1-driven tumorigenesis in various cancer types (reviewed in more detail by Van Dyck et al. 2007a), our understanding of the biological role of PLAG1 in normal physiology is still limited. In this review, we will first summarize what is currently known about the molecular biology of PLAG1 and then integrate the findings of recent studies that provide clues about the biological role of PLAG1 in the endocrine systems coordinating growth and reproduction in particular.

\section{Molecular biology of PLAG1}

\section{Gene and protein structure of PLAG1}

The PLAG1 gene is located on human chromosome $8 \mathrm{q} 12$. Although the predominant PLAG1 transcript is $7.3 \mathrm{~kb}$ long, there are also three shorter splice variants of 7.2, 7.0 and $6.9 \mathrm{~kb}$ (Van Dyck et al. 2007a). In humans, PLAG1 consists of five exons. Exons 4 and 5 contain the coding sequence of $1503 \mathrm{bp}$, which translates to a 500-amino acid protein of $56 \mathrm{kDa}$ (Fig. 1A). The N-terminus of PLAG1 contains seven canonical $\mathrm{C}_{2} \mathrm{H}_{2}$ zinc finger domains responsible for the DNA binding capacity of the protein, and the C-terminus encompasses a serine-rich region that has transcriptional activation activity (Kas et al. 1998, Van Dyck et al. 2007a). Consistent with its role as a transcription factor, PLAG1 has been shown to be a nuclear protein. There are two nuclear localization signals present in its structure; one is the N-terminal zinc finger region, and the other is a karyopherin $\alpha 2$ recognition site in the N-terminus involved in the docking of proteins to the nuclear pores (Braem et al. 2002, Van Dyck et al. 2007a). The predicted mouse PLAG1 protein is $96 \%$ similar to its human homologue. The Ensembl-predicted mouse Plag1 gene is located on chromosome 4 and consists of six exons, with a coding sequence of $1500 \mathrm{bp}$ that encompasses the $3^{\prime}$ end of exon 5 and the $5^{\prime}$ end of exon 6 and translates into a 499 -amino acid protein (Fig. 1B).

The PLAG family contains two additional zinc finger transcription factors, both with known roles in cancer. One, PLAG-like 1 (PLAGL1, also known as LOT1 or ZAC1), is a maternally imprinted tumor-suppressing gene that inhibits tumor cell proliferation through the induction of apoptosis and cell cycle arrest. Ubiquitously expressed in adult human tissues, PLAGL1 is a target of growth factor signaling pathways and its expression is lowered or completely abolished in many types of human cancers (Abdollahi 2007). The other, PLAG-like 2 (PLAGL2), is a proto-oncogene structurally and functionally more similar to PLAG1 (Hensen et al. 2002, Landrette et al. 2005, Van Dyck et al. 2007a), although under certain conditions PLAGL2 has an apoptotic role (Mizutani et al. 2002). The PLAG proteins are most similar in their N-terminal domains, with 73\% identity between PLAG1 and PLAGL1 and 79\% between PLAG1 and PLAGL2. The C-terminus of PLAG1, on the other hand, shows only $19 \%$ identity with that of PLAGL1 and 35\% with PLAGL2. In zebrafish, a plagx gene was identified in addition to plag1 and plagl2 (Pendeville et al. 2006).

\section{Target genes of PLAG1}

Being a transcription factor, PLAG1 acts by altering the transcription rate of target genes. Transient transactivation assays and electrophoretic mobility shift assays have demonstrated that PLAG1 can bind the embryonic P3 promoter of insulin-like growth factor 2 (IGF2) and stimulate its activity, leading to increased IGF2 expression (Voz et al. 2000). Insulin-like growth factor 2 is a growth factor that is essential for normal embryonic growth and its gene is maternally imprinted (DeChiara et al. 1991). Transcripts of IGF2 derived from the P3 promoter were greatly expressed in salivary gland adenomas overexpressing PLAG1 but were undetectable in adenomas without abnormal PLAG1 expression or in normal salivary gland tissue (Voz et al. 2000). Similarly, there is a consistent and significant upregulation of IGF2 expression in PLAG1-overexpressing NIH3T3 and human embryonic kidney 293 (HEK293) cells, in murine salivary tumors induced by Plag1 overexpression, and in hepatoblastomas (Hensen et al. 2002, Zatkova et al. 2004, Declercq et al. 2005). Conversely, PLAG1 overexpression is unable to transform fibroblasts with a targeted disruption of the insulin-like growth factor 1 receptor (IGF1R), required for IGF2 (but also IGF1) function (LeRoith et al. 1995, Hensen et al. 2002). These data have led to the conclusion that PLAG1 influences

Published by Bioscientifica Ltd. 

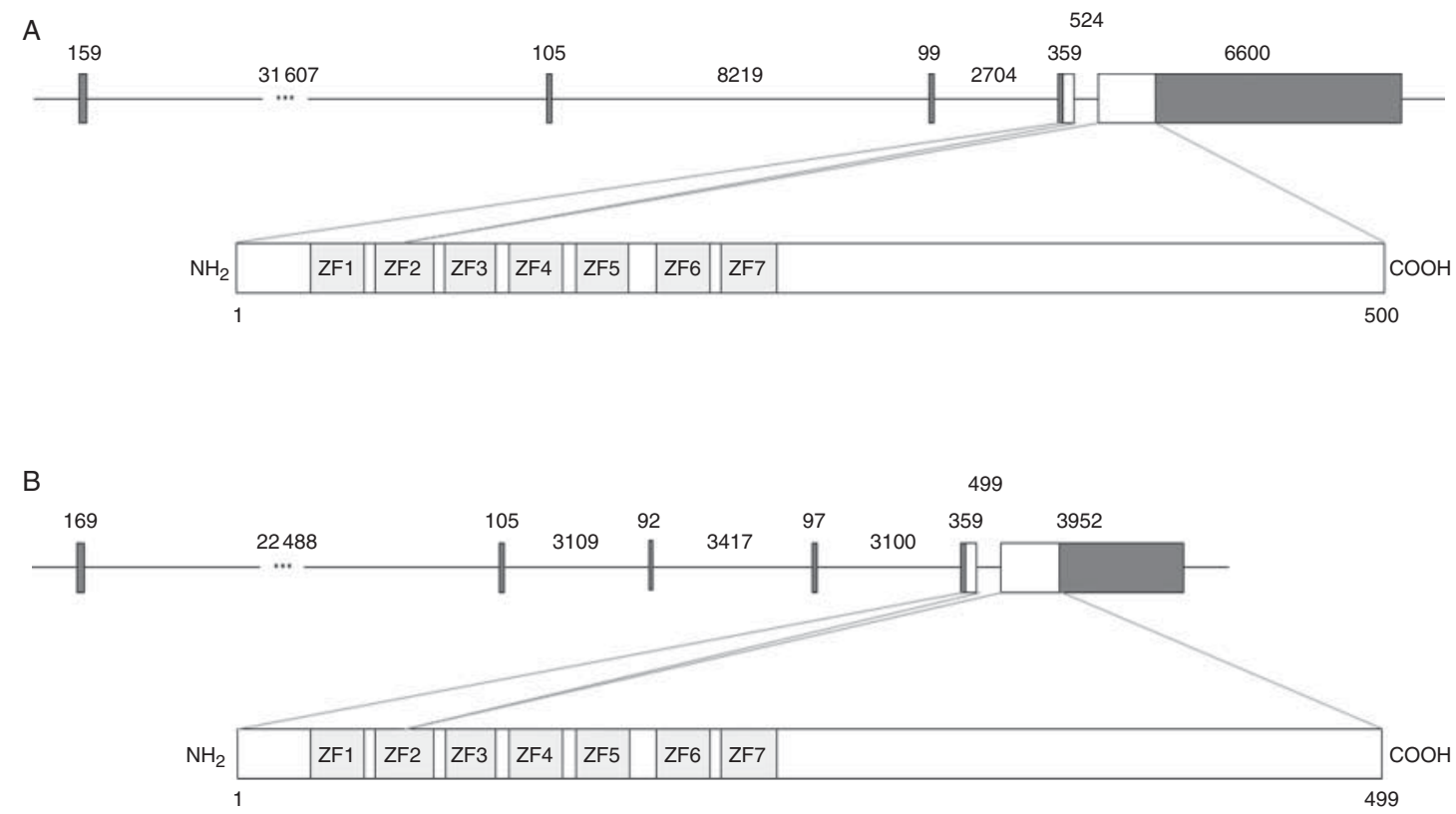

\section{Figure 1}

Schematic representation of the structure of human $(A)$ and predicted mouse (B) PLAG1/Plag1 genes and their proteins. In the gene structures, introns are represented by lines, and exons by boxes. Shaded boxes are the (parts of) exons that encode the untranslated regions; white boxes refer to the protein-coding sequence. Numbers refer to the number of base pairs. In the protein structures, numbers refer to the number of amino acids and

tumorigenesis, at least in part, via the mitogenic action of IGF2, most likely via the activation of IGF1R and the Ras/Raf/MAPK signaling pathway (Hensen et al. 2002, Van Dyck et al. 2007a). It should be noted, however, that the capacity of PLAG1 to bind the IGF2 P3 promoter and increase IGF2 expression is cell type-specific, as overexpression of PLAG1 in the human choriocarcinoma cell line JEG-3 did not result in significant promoter binding or upregulation of IGF2 (Akhtar et al. 2012). An additional role of PLAG1 in the stimulation of IGF2 expression appears to be that of promoter/enhancer facilitator, because PLAG1 induction in these cells was shown to partially overcome the transcription-suppressing effect of the H19 chromatin insulator on the IGF2 P3 promoter in reporter constructs (Akhtar et al. 2012). Moreover, there is evidence that Wnt signaling contributes to PLAG1induced tumorigenesis (Declercq et al. 2008).

To further unravel the molecular mechanism of PLAG1-induced oncogenesis, a microarray containing 12000 human genes was used to screen transcripts expressed in normal salivary glands vs pleomorphic adenomas and compare them to the expression profile of HEK293 cells overexpressing PLAG1 (Voz et al. 2004). The study revealed that 627 genes were differentially expressed lightly shaded boxes indicated by 'ZF' represent the seven zinc finger domains. Structures are based on the Ensembl sequences ENSG00000181690.7 (human PLAG1 gene) and UniProt entry Q6DJT9 (human PLAG1 protein) and Ensembl ENSMUSG00000003282.7 (mouse Plag1 gene) and UniProt entry Q9QYE0 (mouse PLAG1 protein).

in the salivary glands, whereby 254 were downregulated and 373 were upregulated at least threefold in the tumors. These genes were grouped into 14 functional categories, including growth factors, growth factor receptors, growth factor-binding proteins, growth regulation proteins, cell division and cell-cycle related proteins, apoptosis-related proteins, proto-oncogenes, tumor suppressors, transcriptional regulators, signaling proteins, extracellular matrix proteins, and metabolism-related proteins. Notably, most of the upregulated genes were growth factors, growth factor binding proteins and growth factor receptors. The comparison of PLAG1-overexpressing vs normal HEK cells revealed 47 upregulated genes and 12 repressed genes. The combined data showed that 12 genes were consistently upregulated with PLAG1 overexpression: those encoding IGF2 (IGF2); cytokine-like factor 1 (CYTL1); quiescin Q6 sulfhydryl oxidase 1 (QSOX1); cellular retinoic acidbinding protein 2 (CRABP2); SWI/SNF-related, matrixassociated, actin-dependent regulator of chromatin, subfamily d, member 3 (SMARCD3); B-cell CLL/lymphoma 2 (BCL2); cyclin-dependent kinase inhibitor $1 \mathrm{C}(C D K N 1 C)$; ephrin B1 (EFNB1); neuronal pentraxin receptor (NPTXR); collagen, type IX, alpha 3 (COL9A3); the muscle isoform of filamin $\mu \mathrm{C}$, gamma (FLNC); and tetraspanin 4 (TSPAN4).

Published by Bioscientifica Ltd 
In contrast, none of the 12 repressed genes in the PLAG1overexpressing HEK cells were altered in the pleomorphic adenomas (Voz et al. 2004). This again emphasizes that PLAG1 regulates genes in a tissue-specific manner.

Pleomorphic adenoma gene 1 alters the expression levels of its target genes by binding to their regulatory elements. Use of the cyclic amplification and selection of targets (CASTing) strategy revealed a consensus binding motif in PLAG1 target genes composed of a core GRGGC, followed six to eight nucleotides downstream by a cluster of at least three Gs. The GRGGC core of the bipartite sequence is recognized by zinc fingers 6 and 7 of PLAG1, and the $\mathrm{G}$ cluster is bound by zinc finger 3 (Voz et al. 2000). In silico analysis confirmed that the 12 genes identified as direct targets of PLAG1 in salivary glands and HEK cells all possess the PLAG1 binding motif (Voz et al. 2004). Five such binding motifs were found in the P3 promoter of IGF2 (Voz et al. 2000) and eight in the promoter of CYTL1, but most target genes have only one to three (Voz et al. 2004). The genes in which the transcription levels were lowered in PLAG1-overexpressing HEK cells do not appear to be regulated by PLAG1 through direct binding to their promoters, because they lack the target sequence (Voz et al. 2004).

\section{PLAG1 expression patterns}

In general, PLAG1 expression is elevated during the embryonic/fetal period, whereas expression in most adult organs is low or absent, and this has led to the notion of PLAG1 being a 'fetal' transcription factor. Zebrafish Plag genes have low levels of expression during somitogenesis, which then increase and plateau at 5 days post fertilization (Pendeville et al. 2006). Whole-mount in situ hybridization revealed that all three zebrafish plag genes have similar spatial expression patterns characterized by initial low ubiquitous expression, which becomes restricted to zones of active cell proliferation such as the ventricular zone in the brain and the developing pharyngeal arches. In humans, PLAG1 is highly expressed in fetal kidney, liver, and lung, whereas in adult tissues expression was reported either as undetectable (in skeletal muscle, brain, heart, pancreas, lung, and placenta; Kas et al. 1997), or as detectable (in heart, placenta, spleen, prostate, testis, ovary, and small intestine; Queimado et al. 1999) by northern blot analysis. All three Plag genes are expressed in both unique and overlapping patterns in early stages of neural development as determined by in situ hybridization in mice (Alam et al. 2005). Expression in mouse tissues is present until after birth when levels decline as shown by northern blotting. Plag1 transcripts in adult mice were below the detection limit in brain, thymus, stomach, intestines, spleen, prostate, skeletal muscle, kidney, salivary gland, uterus, tongue, lung, and liver (Hensen et al. 2004). In contrast, Plag1 has been detected not only in embryonic but also in adult rat liver using quantitative PCR, albeit at greater levels in the embryonic liver compared to the adult organ (Zheng et al. 2014). This discrepancy with earlier (mouse) studies may be due to species differences or could point to a lower sensitivity of the northern blot technique to assess Plag1 expression. Although Plag1 expression declines drastically after birth to undetectable levels in most mouse tissues, there are some notable exceptions. Expression of Plag1 mRNA has been detected via in situ hybridization and/or PCR in the heart, ovary, testis, vas deferens, and epididymis of adult mice (Hensen et al. 2004). In the gonads, Plag1 expression has been reported in the seminiferous epithelium and isolated Sertoli cells of the testes, as well as in ovarian follicles. Likewise, considerable expression of Plag1 was shown in the embryonic pituitary primordium, which persists in the anterior pituitary of adult mice (Hensen et al. 2004).

\section{Regulation of PLAG1}

Transcription of the PLAG1 gene is itself believed to be controlled by a bidirectional promoter located between the PLAG1 coding sequence and its neighboring gene CHCHD7 (Karim et al. 2011). In cattle, two sequence variants of the PLAG1 promoter with different 'strengths' have been described, relating to a variable number tandem repeat (VNTR) immediately upstream of the presumed PLAG1 transcription start site and a single nucleotide polymorphism (SNP) located $12 \mathrm{bp}$ upstream of the VNTR, in an otherwise highly conserved region (Fig. 2). The VNTR is a $(C C G)_{n}$ trinucleotide repeat with either nine copies (hereafter referred to as the $q$ variant of the promoter) or 11 copies (the $Q$ variant), whereas the SNP is an ' $\mathrm{A}$ ' in the $q$ variant or a ' $\mathrm{G}$ ' in the $Q$ variant (Karim et al. 2011). Luciferase reporter assays have shown that the $Q$ variant of the bovine PLAG1 promoter is consistently $\sim 1.5 \times$ more active than the $q$ variant and that both the Q-type VNTR and the SNP sequence are needed for maximal transcriptional activity. Concordantly, fetal calves of the $Q Q$ genotype show significantly higher expression levels of PLAG1 in the liver, bone, muscle, and brain than $q q$ calves (Karim et al. 2011). The effects of the VNTR and SNP on promoter strength are most likely

Published by Bioscientifica Ltd. 


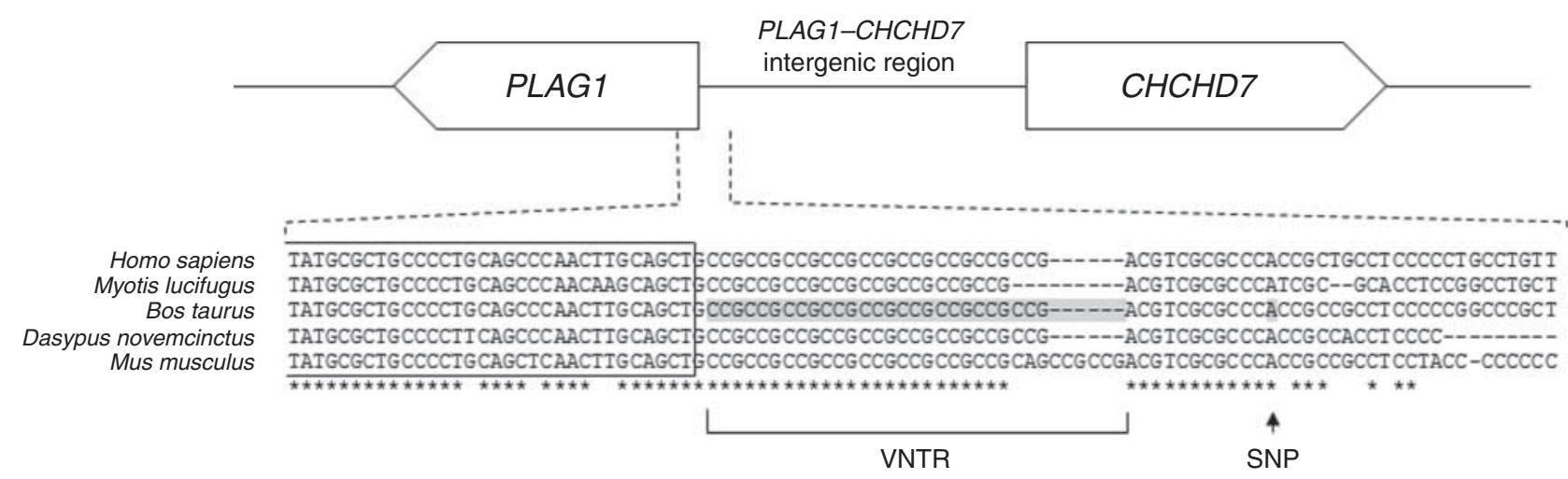

Figure 2

Sequence variants that affect the strength of the bidirectional promoter located in the PLAG1-CHCHD7 intergenic region in cattle. In cattle, the $Q$ variant of the promoter, in which the 'CCG' sequence in the VNTR is repeated 11 times and the SNP is ' $G$ ', leads to higher transcriptional activity of the promoter compared to the $q$ variant in which the VNTR is repeated nine times and the SNP is ' $A$ ' (as shown, shaded). This genomic region is

caused by differential binding of trans-acting factors, as suggested by electrophoretic mobility shift assays. A number of complexes of nuclear proteins and promoter probes was seen in all tissues and cell lines tested, indicating that widely expressed trans-acting factors are involved. Some complexes, however, were tissue specific, and with nuclear extracts from the mouse myoblast C2C12 cell line, a Q-specific complex was observed that did not form with the $q$ promoter variant (Karim et al. 2011). It is not known whether the same PLAG1 promoter polymorphisms exist in species other than cattle.

In addition to transcriptional regulation, PLAG1 activity is also controlled by different posttranscriptional mechanisms. Posttranslational modification of transcription factors is known to affect their transactivation capacity. Posttranslational deacetylation and SUMOylation, the reversible attachment of a small ubiquitin-like modifier (SUMO) protein, have been shown to inhibit the transactivation function of PLAG1, whereas acetylation activates it (Van Dyck et al. 2004, Zheng \& Yang 2005). It has been postulated that these regulatory mechanisms change the affinity of co-repressors and co-activators (Van Dyck et al. 2007a). SUMOylation may also influence the nuclear localization of PLAG1, but contradictory results have been reported (Van Dyck et al. 2004, Zheng \& Yang 2005). Furthermore, the C-terminal serine-rich transactivation domain of PLAG1 possesses phosphorylation sites, raising the possibility that phosphorylation may regulate the transactivation capacity of PLAG1 (Van Dyck et al. 2007a). otherwise highly conserved, as demonstrated by the comparison of the cattle (Bos taurus) sequence with that of human (Homo sapiens), little brown bat (Myotis lucifugus), nine-banded armadillo (Dasypus novemcinctus), and mouse (Mus musculus). Reprinted by permission from Macmillan Publishers Ltd: Nature Genetics (Karim et al. 2011), copyright 2011.

Recently, it was shown that expression of PLAG1 is also regulated by microRNAs (miRNAs). These short ( $22 \mathrm{bp}$ ), non-coding, double-stranded RNA molecules bind to target mRNAs, most often to a binding site located in their $3^{\prime}$ untranslated regions ( $3^{\prime}$ UTRs), leading to translational repression or mRNA decay. Target prediction of miRNAs found to be deregulated in B cells from chronic lymphocytic leukemia patients led to the discovery of nine highly conserved and eight less conserved putative miRNA binding sites in the 3'UTR of PLAG1 (Pallasch et al. 2009). It was subsequently confirmed that PLAG1 expression is regulated by miR-107, $-141,-155,-181 a,-181 b$, and -424 . Transcriptional silencing of some of these miRNAs due to hypermethylation of their promoters is thought to result in overexpression of PLAG1, ultimately leading to chronic lymphocytic leukemia. In B cells of chronic lymphocytic leukemia patients, PLAG1 mRNA levels were not different to those in healthy donor B cells, but PLAG1 protein levels were indeed upregulated, suggesting that the miRNAs control PLAG1 levels primarily by translational repression rather than mRNA breakdown (Pallasch et al. 2009). Upregulation of miR-141 in the placentas of human fetuses suffering intrauterine growth restriction, on the other hand, was found to be associated with downregulation of placental PLAG1 mRNA and protein levels (Tang et al. 2013). Based on a significant correlation between PLAG1 and IGF2 expression levels also seen in these placentas, the authors of this study proposed that development of fetal growth restriction may be due in part to a deregulation of a miR-141-PLAG1-IGF2 pathway.

Published by Bioscientifica Ltd 


\section{Role of PLAG1 in growth}

\section{Evidence from in vivo studies}

To elucidate the role of PLAG1 in embryonic development, a Plag1 knockout (KO) mouse strain was generated in which both alleles of Plag1 are inactivated by targeted disruption by homologous recombination (Hensen et al. 2004). One of the most prominent features of the $\mathrm{KO}$ phenotype is reduced body size (Fig. 3). Although Plag1deficient mice are viable, they are significantly smaller at birth compared to WT mice (Hensen et al. 2004). A size difference of $18 \%$ was detectable as early as embryonic day 11.5 , and by the end of gestation, mutants were $\sim 30 \%$ smaller. This difference in body size augmented during postnatal growth with mutants being up to $50 \%$ smaller at postnatal day 21. After weaning, the growth rate of the Plag1-deficient animals increased such that the difference in body weight at postnatal day 60 was back to $30 \%$

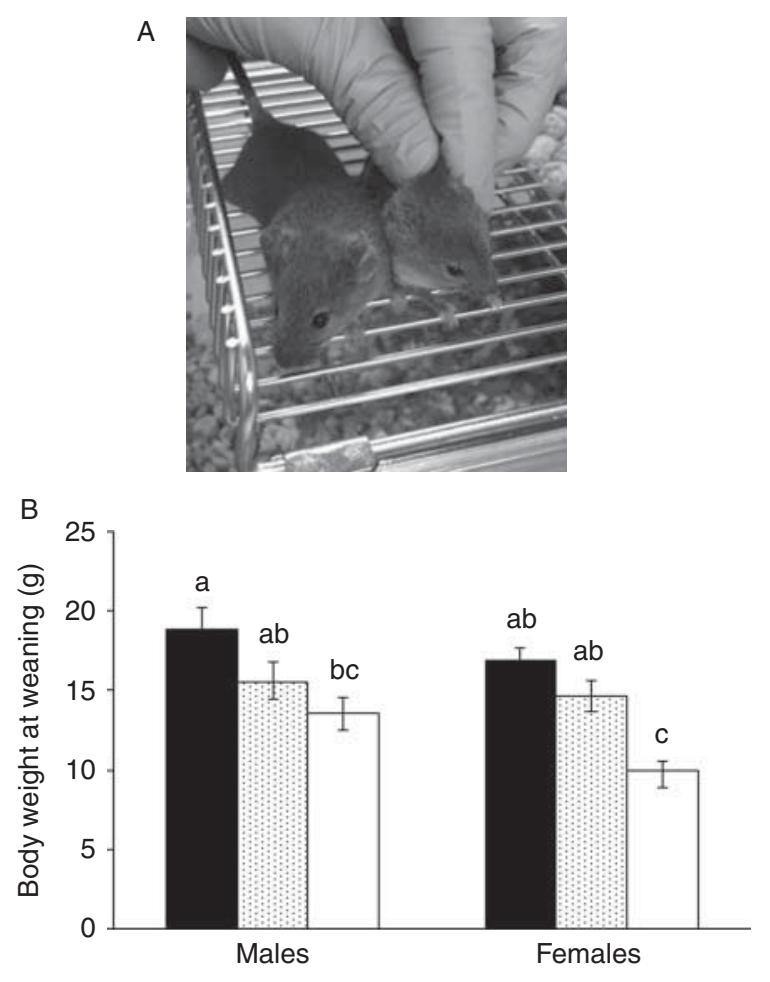

Figure 3

(A) Phenotype of a female Plag1 knockout mouse (right) compared to a heterozygous female littermate (left) at the age of $\sim 45$ days. (B) Body weights (in grams) of male and female WT (black bars), heterozygous (dotted bars) and knockout (white bars) mice at weaning (P E Damdimopoulou, unpublished results). Values are means \pm s.E.M. $(n=6-13)$. Data without a common letter are significantly different $(P<0.05$, ANOVA and post-hoc Tukey's honest significant difference (HSD) test). Two-way ANOVA revealed an effect of both sex and genotype on body weight but no sex $\times$ genotype interaction. smaller than the WT mice. Notably, the weight of most organs of $\mathrm{KO}$ mice was proportionate to body weight, apart from the ventral prostate and seminal vesicles, which were significantly smaller. Despite detection of Plag1 expression in the placenta and testis of WT mice, no significant difference in organ weight relative to body weight was noted in these organs in mutants (Hensen et al. 2004). It is possible that some of the effects of Plag1 deficiency were compensated for by functionally redundant genes like Plagl2. Pleomorphic adenoma gene 1 and PLAGL2 both possess similar DNA binding affinities, have common downstream target genes such as $I g f 2$, and, at least in some tissues, have overlapping spatial and temporal expression patterns (Kas et al. 1997, 1998, Hensen et al. 2002, Landrette et al. 2005). Surprisingly, the Plagl2 KO mouse has a much more severe phenotype. $\mathrm{KO}$ animals exhibit high neonatal lethality due to a failure of fat absorption, and this prevents studies of the specific role of PLAGL2 in adult mice. It is believed that PLAG1 and PLAGL2 are functionally redundant during embryonic/ fetal development but not postnatally, when PLAG1 levels are very low (Van Dyck et al. 2007b).

\section{Evidence from genome-wide association studies}

The importance of PLAG1 in growth is further supported by a range of recent genome-wide association studies (GWASs) in humans and cattle. A SNP in the chromosome fragment containing PLAG1 and its neighboring genes was identified as 1 of 27 loci that showed the strongest correlation with adult human height in a meta-analysis of 39510 (mostly Caucasian) individuals (Gudbjartsson et al. 2008). Similarly, SNPs in the PLAG1 chromosomal region were found to correlate with human height in Asian populations (Cho et al. 2009, Okada et al. 2010). Prior to these discoveries in humans, a myriad of genomic studies had identified a region on bovine chromosome 14 as having a significant effect on growth-related traits in cattle (Wibowo et al. 2008). It was subsequently shown that the loci associated with height in humans are also associated with stature in cattle (Pryce et al. 2011). The region on chromosome 14 that was consistently found to affect cattle stature (or related traits such as hip height, live weight at birth and at various other ages, growth rate, body condition score, and carcass weight) contains the bovine PLAG1 homologue, among other genes (Karim et al. 2011, Pausch et al. 2011, Pryce et al. 2011, Hawken et al. 2012, Littlejohn et al. 2012, Nishimura et al. 2012, Fortes et al. 2013a, Utsunomiya et al. 2013). The association of body weight with the chromosome 14

Published by Bioscientifica Ltd 
region was already detectable at birth (Karim et al. 2011). A co-localized effect on height was observed, but because no association was found with the weight:height ratio, it was concluded that the PLAG1-containing chromosomal region affects stature rather than weight per se. Karim et al. (2011) were able to narrow down the stature-affecting sequences on bovine chromosome 14 to a small number of polymorphisms in the vicinity of the PLAG1 gene, most notably the VNTR and SNP in the PLAG1 promoter (the $Q$ and $q$ variants) mentioned earlier, as well as a SNP in the $3^{\prime}$ UTR of PLAG1. For each $Q$ variant of the promoter present (i.e., the sequence variant proven to result in greater PLAG1 transcription levels; see above), an additional $\sim 20 \mathrm{~kg}$ in body weight and $\sim 2 \mathrm{~cm}$ in body height were observed in the cattle under investigation, resulting in a difference between full-grown $Q Q$ and $q q$ animals of $\sim 40 \mathrm{~kg}$ and $\sim 4 \mathrm{~cm}$ (Karim et al. 2011). Similarly, newborn homozygous $Q Q$ and heterozygous Qq dairy calves were found to be 18.8 and $10.4 \%$ heavier, respectively, compared to homozygous $q q$ calves (Littlejohn et al. 2012). Variants of PLAG1 have also been suggested to contribute to body size in European domestic pigs and horses (Rubin et al. 2012, Metzger et al. 2013), indicating that this role of PLAG1 is likely to be conserved across mammals. It should be emphasized, however, that although PLAG1 was found to be the most plausible candidate on chromosome 14 as the causative gene for stature differences in cattle, other genes in the vicinity of PLAG1, such as RPS20, MOS, RDHE2, SDR16C6, and PENK, some of which having established links with growth, were also differentially expressed in the fetal tissues of $Q Q$ and $q q$ animals (Karim et al. 2011).

\section{Possible mechanisms linking PLAG1 to growth}

Whereas evidence for an important role of PLAG1 in mammalian growth is increasing, the underlying mechanisms are somewhat elusive. This is likely to stem, in part, from the demonstrated effects of PLAG1 on IGF2 expression levels in the cell culture and cancer studies mentioned before. Insulin-like growth factors regulate pathways involved in cell proliferation and differentiation and are well known as key regulators of normal fetal development and growth. The control of fetal growth by IGF2 occurs both directly at the level of cell proliferation in the fetusand indirectly at the level of the placenta, where, because of its effects on placental structure and physiology, the supply of maternal nutrients to the fetus is affected (Reik et al. 2001). Insulin-like growth factor 2 also functions in cardiac development, myogenesis, vasculogenesis, and bone growth and development (Minuto et al. 2004, Wilson \& Rotwein 2006, Harris \& Westwood 2012). Therefore, it is generally assumed that the role of PLAG1 in growth is mainly a reflection of its capacity to increase the expression of IGF2 (at least in some cell types; see above) and other growth factors. Indeed, like murine IGF2 (but unlike human IGF2) (LeRoith \& Roberts 2003), PLAG1 is predominantly expressed in fetal tissues and declines thereafter. In addition, Plag1-deficient mice show remarkable phenotypic similarities with $I g f 2^{+/ p-}$ mice in which the disruption of the paternal $I g f 2$ allele resulted in an $\sim 40 \%$ size reduction compared to WT littermates (DeChiara et al. 1990). In both mouse lines, the size differences were first detected at embryonic day 11.5 and the growth retardation was maintained throughout life (or the observation period). Furthermore, the absence of an association between PLAG1 polymorphisms and growth rate relative to body weight in dairy cattle GWASs indicates that the differences in the growth rate observed in $Q Q$ and $q q$ calves are partly due to initial differences in size, meaning that the effect of PLAG1 on growth is likely to occur mainly during fetal development (Karim et al. 2011, Littlejohn et al. 2012). For the trait 'post-weaning live weight' in beef cattle, epistatic interactions of the PLAG1 polymorphisms with other genes were noted, including IGF2 and Insulin (Bolormaa et al. 2015). Taken together, these observations make a strong case for the involvement of IGF2 in the growth effect of PLAG1, but direct evidence is nevertheless lacking. Intriguingly, Igf2 expression levels (at least as measured by northern blot in whole animals) were not significantly altered in Plag1 KO embryos and pups, nor were placenta weights as compared WT embryos (Hensen et al. 2004). It remains to be investigated whether local IGF2 mRNA or protein levels within tissues differ between Plag1 KO and WT animals. In addition, possible effects in tissues such as placenta should be studied in more detail through histology and gene expression analyses. It is also possible that PLAG1 affects growth in additional ways that do not involve IGF2, but these pathways are currently unknown and unexplored.

\section{Role of PLAG1 in fertility and reproduction}

\section{Evidence from in vivo studies}

In addition to growth retardation, both male and female Plag1 KO mice were found to have reduced fertility (Hensen et al. 2004). Males deficient in Plag1 were able to fertilize only $7 \%$ of WT females compared to $20 \%$ by

Published by Bioscientifica Ltd. 
WT males. KO females, on the other hand, had normal conception rates, but up to $50 \%$ reduced average litter size compared to WT females when mated to WT males. The mating of male and female Plag1 mutants with each other resulted in small litters and infrequent conception (Hensen et al. 2004). Pleomorphic adenoma gene 1 is expressed in both male and female gonads in the adult mouse, as well as in the pituitary gland (Hensen et al. 2004). It will be important to study where along the hypothalamo-pituitary gonadal (HPG) axis the effects of Plag1 primarily take place, leading to the observed reduced fertility in both sexes. In the chicken, PLAG1 was identified among nine genes differentially expressed in the hypothalamo-pituitary system of high- and lowproducing layer strains. Greater PLAG1 expression levels were associated with a higher number of eggs up to 50 weeks of age, a higher frequency of egg laying after the first egg, and/or a shorter average pause length between laying (Shiue et al. 2006, Chen et al. 2007a,b). Because these studies used a mixture of hypophyseal and hypothalamic RNA, it is impossible to determine whether the differential expression relates to pituitary PLAG1, hypothalamic PLAG1, or both and thus may involve gonadotrophs, gonadotropin-releasing hormone (GnRH) neurons and/or other cell types. Because no functional studies were carried out, the mechanism connecting greater PLAG1 expression to increased egg production in the chicken is unknown, and even though the hormones involved in the reproduction in chicken have, in general terms, similar functions to those in mammals, one should be careful to extrapolate these findings over the species borders.

\section{Evidence from GWAS studies}

While a role for PLAG1 in human fertility is yet to be established, GWASs have found links between puberty onset and PLAG1 (or chromosome 14) polymorphisms in cattle (Fortes et al. 2012a,b, 2013a,b,c, Hawken et al. 2012, Bolormaa et al. 2015). A number of genetic markers for the onset of puberty mapped to the PLAG1-containing region on chromosome 14 in Brahman cows (determined as the age at which the first corpus luteum was detected) and bulls (determined as scrotal circumference or age at a scrotal circumference of $26 \mathrm{~cm}$ ) (Fortes et al. 2012a,b, 2013b, Hawken et al. 2012). Interestingly, a number of GWASs have shown that sequence variants in the PLAG1 chromosomal region in cattle are associated not only with the growth- and reproduction-related traits discussed above but also with circulating IGF1 concentrations. The $Q$ variant, which is associated with increased body size and higher PLAG1 expression, correlates to lower IGF1 levels in the blood and later onset of puberty (Fortes et al. 2012a,b, 2013b, Hawken et al. 2012). Other reproduction-related traits, such as plasma inhibin levels at 4 months of age, plasma luteinizing hormone (LH) levels following GnRH challenge at 4 months, and sperm quality, showed no obvious associations with the PLAG1 region (Fortes et al. $2012 b, 2013 b$ ). Like always in the case of GWASs, one should bear in mind that the causality between detected polymorphisms and a phenotype cannot be deduced with certainty. For example, it is possible that the polymorphisms in bovine chromosome 14 do not affect only PLAG1 but also other genes in the vicinity of PLAG1. Some of the genes neighboring PLAG1 do indeed have known effects on reproduction (Fortes et al. 2012b).

\section{Possible mechanisms linking PLAG1 to reproductive physiology}

The presence of PLAG1 is required for normal fertility in both male and female, as suggested by the Plag1 KO mice. At present it is not known through which mechanisms PLAG1 regulates reproduction, but clues in the literature suggests that regulation on multiple levels of the HPG axis is possible (Fig. 4).

Expression of Plag1 is observed in the urogenital ridge and ovaries of 11.5- and 16.5-day-old mouse embryos respectively (Hensen et al. 2004), which may suggest that PLAG1 has a role in the development and differentiation of the reproductive tract or in the establishment of the ovarian germ cell pool. Spermatogenesis and ovarian follicle maturation have not been studied in the $\mathrm{KO}$ animals so far but were assumed to be normal in $\mathrm{KO}$ mice because no gross morphological changes were observed in the gonads (Hensen et al. 2004). The KO males have smaller relative ventral prostate and seminal vesicle weights compared to WT littermates, which could suggest that Plag1 is required for normal androgen balance in the male. Neither ventral prostate nor seminal vesicles express detectable levels of Plag1 in adult animals, which support an indirect mode of action on these organs. Involvement of Plag1 in, for instance, steroidogenesis should be evaluated in future studies.

High expression levels of Plag1 were noted in the embryonic and adult anterior pituitary of mice (Hensen et al. 2004). The gonadotrophs, producing LH and folliclestimulating hormone, reside in this part of the pituitary gland. However, immunostaining of LH cells in pituitaries from Plag1 KO and WT mice did not reveal obvious differences in the number of LH cells (Hensen et al. 2004).

Published by Bioscientifica Ltd. 
Higher PLAG1 expression levels in hypothalamo-pituitary system of chickens associated with higher egg laying

High expression level of Plag1 in adult mouse pituitary

Number of LH and GH cells in pituitary of Plag1 KO mice normal
IGF1-mediated delay of Kiss 1 expression? Effect on Kiss 1 synthesis and/or secretion? Effect on neuron number?

GF1-mediated delay of Gnrh expression? Effect on GnRH synthesis and/or secretion, or kisspeptin sensitivity? Effect on neuron number?

\section{Figure 4}

Interactions of PLAG1 with the hypothalamo-pituitary-gonadal axis, displaying known interactions on the left and possible mechanisms that remain to be investigated on the right. $\mathrm{FSH}$, follicle-stimulating hormone; $\mathrm{GH}$, growth hormone; KO, knockout. Reproduced, with permission, from

Measurement of a wider selection of hormones, in both the male and the female, would reveal more about Plag1 as a regulator of the HPG axis. In addition, the striking growth retardation phenotype of the $\mathrm{KO}$ animals calls for an evaluation of the growth hormone $(\mathrm{GH})$ levels in the animals. Like gonadotropins, GH is secreted by the anterior pituitary where Plag1 is expressed. In addition, $\mathrm{GH}$ has a direct effect on the IGF system that regulates reproductive physiology (Baker et al. 1996, Zhou et al. 1997, Hull \& Harvey 2000, 2001, Pitetti et al. 2013, Zhou et al. 2013, Wolfe et al. 2014) and that has been systematically identified as a target of Plag1. However, Plag1 KO mice do not seem to have a lower number of hypophyseal GH cells (Hensen et al. 2004).

As discussed earlier in this review, IGF2 is a direct target of PLAG1, but IGF1 also appears to have a connection to PLAG1. Bovine $Q Q$ genotypes, which show a higher expression of PLAG1, are significantly associated with lower circulating IGF1 levels in the animals (Fortes et al. 2012a,b, 2013b, Hawken et al. 2012). It is generally accepted that IGF1, be it of peripheral or central origin, affects the onset of puberty, which in
Pinilla L, Aguilar E, Dieguez C, Millar RP \& Tena-Sempere M (2012) Kisspeptins and reproduction: physiological roles and regulatory mechanisms. Physiology Reviews 92 1235-1316. Copyright 2012, American Physiological Society.

endocrinological terms equates to the re-activation of the GnRH neurons after adolescence (DiVall et al. 2010, Wolfe et al. 2014). In addition to a direct effect at the level of the GnRH neurons, IGF1 may also stimulate GnRH neuronal activity through the kisspeptin neurons upstream of the GnRH neurons (Hiney et al. 2009, Pinilla et al. 2012). The later onset of puberty in cattle that display both a higher expression of PLAG1 and lower IGF1 levels is an intriguing finding, and the mechanism that connects these two molecules should be studied in experimental systems. To start with, IGF1 levels and puberty onset could be studied in the existing $\mathrm{KO}$ mouse model.

Effects of PLAG1 on puberty onset through $\mathrm{GH}$ signaling should be further studied too. In prepubertal beef heifers, immunization against $\mathrm{GH}$-releasing hormone causes a reduction in serum IGF1 concentrations and delays puberty (Simpson et al. 1991). It seems paradoxical that the same $Q$ polymorphism that leads to higher PLAG1 expression levels is associated with both delayed puberty and increased growth. Body size and growth rate are the two major factors affecting the onset of puberty in cattle: puberty is delayed until the heifer possesses an adequate

Published by Bioscientifica Ltd. 
body size to successfully reproduce (Velazquez et al. 2008). One would expect the animals with higher levels of PLAG1 to reach this 'threshold' body size earlier and thus commence puberty faster. It has been proposed that IGF1R expression levels may be higher in these individuals, thus increasing the sensitivity of target tissues to IGF1 stimulation (Fortes et al. 2013a). In this scenario, however, PLAG1 may have to increase IGF1R levels in certain targets tissues only, but not in others (such as the GnRH and kisspeptin neurons). Finally, the many negative feedback loops of the endocrine system could lead to a situation in which a measurement of a single hormone or growth factor does not show the whole picture. Measurement of hypothalamic and pituitary hormones along with the IGF1 and sex steroids at different stages of sexual maturity will be essential in understanding the reproductive effects of PLAG1 in more detail.

\section{Summary and future perspectives}

In summary, there is increasing evidence that the transcription factor PLAG1 plays a role in both growth and reproduction. The role of PLAG1 in mammalian growth is supported by a KO mouse model as well as numerous GWASs in human and particularly in cattle, where one study (Karim et al. 2011) has shown that genetic polymorphisms in the PLAG1 gene promoter lead to higher expression levels of PLAG1 in fetal tissues, such as muscle and bone, and correlates with a larger stature. It is likely that the effect of PLAG1 on stature and related traits is the result of its transcriptional control over a range of genes involved in growth and cell proliferation, most notably IGF2. A role for PLAG1 in both male and female fertility has been suggested by the KO mouse model and GWASs in cattle. The mechanisms have not been studied in detail thus far but could be related to GH and IGF1/IGF2 signaling as well as steroidogenesis. In other words, PLAG1 is likely to have effects on more than one level of the HPG axis, and the same mechanisms could be involved in the reported effects of PLAG1 on growth and fertility. More functional studies should be carried out to reveal the exact role of PLAG1 as a regulator of growth and reproductive physiology.

\section{Declaration of interest}

The authors declare that there is no conflict of interest that could be perceived as prejudicing the impartiality of this review.

\section{Funding}

This work was supported by the ANZ Trustees' Medical Research \& Technology in Victoria program (grant number CT 20677).
Acknowledgements

The authors thank Dr Simon Watson for his advice regarding statistical analyses.

\section{References}

Abdollahi A 2007 LOT1 (ZAC1/PLAGL1) and its family members: mechanisms and functions. Journal of Cellular Physiology 210 16-25. (doi:10.1002/jcp.20835)

Akhtar M, Holmgren C, Göndör A, Vesterlund M, Kanduri C, Larsson C \& Ekström TJ 2012 Cell type and context-specific function of PLAG1 for IGF2 P3 promoter activity. International Journal of Oncology $\mathbf{4 1}$ 1959-1966. (doi:10.3892/ijo.2012.1641)

Alam S, Zinyk D, Ma L \& Schuurmans C 2005 Members of the Plag gene family are expressed in complementary and overlapping regions in the developing murine nervous system. Developmental Dynamics 234 772-782. (doi:10.1002/dvdy.20577)

Åström A-K, Voz ML, Kas K, Röijer E, Wedell B, Mandahl N, Van de Ven W, Mark J \& Stenman G 1999 Conserved mechanism of PLAG1 activation in salivary gland tumors with and without chromosome $8 \mathrm{q} 12$ abnormalities identification of SII as a new fusion partner gene. Cancer Research 59 918-923.

Åström A, d'Amore ES, Sainati L, Panarello C, Morerio C, Mark J \& Stenman G 2000 Evidence of involvement of the PLAG1 gene in lipoblastomas. International Journal of Oncology 16 1107-1117. (doi:10.3892/ijo.16.6.1107)

Baker J, Hardy MP, Zhou J, Bondy C, Lupu F, Bellvé AR \& Efstratiadis A 1996 Effects of an Igf1 gene null mutation on mouse reproduction. Molecular Endocrinolgy 10 903-918. (doi:10.1210/mend.10.7.8813730)

Bolormaa S, Pryce JE, Zhang Y, Reverter A, Barendse W, Hayes BJ \& Goddard ME 2015 Non-additive genetic variation in growth, carcass and fertility traits of beef cattle. Genetique, Selection, Evolution 4726. (doi:10.1186/s12711-015-0114-8)

Braem CV, Kas K, Meyen E, Debiec-Rychter M, Van de Ven WJM \& Voz ML 2002 Identification of a karyopherin $\alpha 2$ recognition site in PLAG1, which functions as a nuclear localization signal. Journal of Biological Chemistry 277 19673-19678. (doi:10.1074/jbc.M112112200)

Chen L-R, Chao C-H, Chen C-F, Lee Y-P, Chen Y-L \& Shiue Y-L $2007 a$ Expression of 25 high egg production related transcripts that identified from hypothalamus and pituitary gland in red-feather Taiwan country chickens. Animal Reproduction Science 100 172-185. (doi:10.1016/ j.anireprosci.2006.07.005)

Chen C-F, Shiue Y-L, Yen C-J, Tang P-C, Chang H-C \& Lee Y-P $2007 b$ Laying traits and underlying transcripts, expressed in the hypothalamus and pituitary gland, that were associated with egg production variability in chickens. Theriogenology 68 1305-1315. (doi:10.1016/j.theriogenology. 2007.08.032)

Cho YS, Go MJ, Kim YJ, Heo JY, Oh JH, Ban H-J, Yoon D, Lee MH, Kim D-J, Park M et al. 2009 A large-scale genome-wide association study of Asian populations uncovers genetic factors influencing eight quantitative traits. Nature Genetics 41 527-534. (doi:10.1038/ng.357)

DeChiara TM, Efstratiadis A \& Robertsen EJ 1990 A growth-deficiency phenotype in heterozygous mice carrying an insulin-like growth factor II gene disrupted by targeting. Nature 345 78-80. (doi:10.1038/ 345078a0)

DeChiara TM, Robertson EJ \& Efstratiadis A 1991 Parental imprinting of the mouse insulin-like growth factor II gene. Cell 64 849-859. (doi:10.1016/0092-8674(91)90513-X)

Declercq J, Van Dyck F, Braem CV, Van Valckenborgh IC, Voz M, Wassef M, Schoonjans L, Van Damme B, Fiette L \& Van de Ven WJM 2005 Salivary gland tumors in transgenic mice with targeted PLAG1 proto-oncogene overexpression. Cancer Research 65 4544-4553. (doi:10.1158/00085472.CAN-04-4041)

Published by Bioscientifica Ltd. 
Declercq J, Van Dyck F, Van Damme B \& Van de Ven WJM 2008 Upregulation of Igf and Wnt signalling associated genes in pleomorphic adenomas of the salivary glands in PLAG1 transgenic mice. International Journal of Oncology 32 1041-1047. (doi:10.3892/ ijo.32.5.1041)

DiVall SA, Williams TR, Carver SE, Koch L, Brüning JC, Kahn CR, Wondisford F, Radovick S \& Wolfe A 2010 Divergent roles of growth factors in the GnRH regulation of puberty in mice. Journal of Clinical Investigations 120 2900-2909. (doi:10.1172/JCI41069)

Fortes MRS, Lehnert SA, Bolormaa S, Reich C, Fordyce G, Corbet NJ, Whan V, Hawken RJ \& Reverter A 2012a Finding genes for economically important traits: Brahman cattle puberty. Animal Production Science 52 143-150. (doi:10.1071/AN11165)

Fortes MR, Reverter A, Hawken RJ, Bolormaa S \& Lehnert SA $2012 b$ Candidate genes associated with testicular development, sperm quality, and hormone levels of inhibin, luteinizing hormone, and insulin-like growth factor 1 in Brahman bulls. Biology of Reproduction 87 58. (doi:10.1095/biolreprod.112.101089)

Fortes MRS, Kemper K, Sasazaki S, Reverter A, Pryce JE, Barendse W, Bunch R, McCulloch R, Harrison B, Bolormaa S et al. 2013a Evidence for pleiotropism and recent selection in the PLAG1 region in Australian Beef cattle. Animal Genetics 44 636-647. (doi:10.1111/age.12075)

Fortes MRS, Reverter A, Kelly M, McCulloch R \& Lehnert SA 2013b Genome-wide association study for inhibin, luteinizing hormone, insulin-like growth factor 1, testicular size and semen traits in bovine species. Andrology 1 644-650. (doi:10.1111/j.2047-2927.2013.00101.x)

Fortes MR, DeAtley KL, Lehnert SA, Burns BM, Reverter A, Hawken RJ, BoeHansen G, Moore SS \& Thomas MG 2013c Genomic regions associated with fertility traits in male and female cattle: Advances from microsatellites to high-density chips and beyond. Animal Reproduction Science 141 1-19. (doi:10.1016/j.anireprosci.2013.07.002)

Gudbjartsson DF, Walters GB, Thorleifsson G, Stefansson H, Halldorsson BV, Zusmanovich P, Sulem P, Thorlacius S, Gylfason A, Steinberg S et al. 2008 Many sequence variants affecting diversity of adult human height. Nature Genetics 40 609-615. (doi:10.1038/ng.122)

Harris LK \& Westwood M 2012 Biology and significance of signalling pathways activated by IGF-II. Growth Factors 30 1-12. (doi:10.3109/ 08977194.2011.640325)

Hawken RJ, Zhang YD, Fortes MRS, Collis E, Barris WC, Corbet NJ, Williams PJ, Fordyce G, Holroyd RG, Walkley JRW et al. 2012 Genomewide association studies of female reproduction in tropically adapted beef cattle. Journal of Animal Science 90 1398-1410. (doi:10.2527/jas. 2011-4410)

Hensen K, Van Valckenborgh IC, Kas K, Van de Ven WJM \& Voz ML 2002 The tumorigenic diversity of the three PLAG family members is associated with different DNA binding capacities. Cancer Research 62 1510-1517

Hensen K, Braem C, Declercq J, Van Dyck F, Dewerchin M, Fiette L, Denef C $\&$ Van de Ven WJM 2004 Targeted disruption of the murine Plag1 proto-oncogene causes growth retardation and reduced fertility. Development, Growth and Differentiation 46 459-470. (doi:10.1111/ j.1440-169x.2004.00762.x)

Hiney JK, Srivastava VK, Pine MD \& Dees WL 2009 Insulin-like growth factor-I activates KiSS-1 gene expression in the brain of the prepubertal female rat. Endocrinology 150 376-384. (doi:10.1210/en.2008-0954)

Hull KL \& Harvey S 2000 Growth hormone: roles in male reproduction. Endocrine 13 243-250. (doi:10.1385/ENDO:13:3:243)

Hull KL \& Harvey S 2001 Growth hormone: roles in female reproduction. Journal of Endocrinology 168 1-23. (doi:10.1677/joe.0.1680001)

Karim L, Takeda H, Lin L, Druet T, Arias JA, Baurain D, Cambisano N, Davis SR, Farnir F, Grisart B et al. 2011 Variants modulating the expression of a chromosome domain encompassing PLAG1 influence bovine stature. Nature Genetics 43 405-413. (doi:10.1038/ng.814)

Kas K, Voz ML, Röijer E, Åström A-K, Meyen E, Stenman G \& Van de Ven WJM 1997 Promoter swapping between the genes for a novel zinc finger protein and $\beta$-catenin in pleiomorphic adenomas with $\mathrm{t}(3 ; 8)(\mathrm{p} 21 ; \mathrm{q} 12)$ translocations. Nature Genetics 15 170-174. (doi:10.1038/ng0297-170)

Kas K, Voz ML, Hensen K, Meyen E \& Van de Ven WJM 1998 Transcriptional activation capacity of the novel PLAG family of zinc finger proteins. Journal of Biological Chemistry 273 23026-23032. (doi:10.1074/jbc.273.36.23026)

Landrette SF, Kuo Y-H, Hensen K, Barjesteh van Waalwijk van DoornKhosrovani S, Perrat PN, Van de Ven WJM, Delwel R \& Castilla LH 2005 Plag1 and Plagl2 are oncogenes that induce acute myeloid leukemia in cooperation with Cbfb-MYH11. Blood 105 2900-2907. (doi:10.1182/ blood-2004-09-3630)

LeRoith D \& Roberts CT 2003 The insulin-like growth factor system and cancer. Cancer Letters 195 127-137. (doi:10.1016/S03043835(03)00159-9)

LeRoith D, Werner H, Beitner-Johnson D \& Roberts Molecul Jr AT 1995 lar and cellular aspects of the insulin-like growth factor I receptor. Endocrine Reviews 16 143-163. (doi:10.1210/edrv-16-2-143)

Littlejohn M, Grala T, Sanders K, Walker C, Waghorn G, Macdonald K, Coppieters W, Georges M, Spelman R, Hillerton E et al. 2012 Genetic variation in PLAG1 associates with early life body weight and peripubertal weight and growth in Bos taurus. Animal Genetics 45 591-594. (doi:10.1111/j.1365-2052.2011.02293.x)

Metzger J, Philipp U, Lopes MS, da Camara Machado A, Felicetti M, Silvestrelli M \& Distl O 2013 Analysis of copy number variants by three detection algorithms and their association with body size in horses. BMC Genomics 14 487. (doi:10.1186/1471-2164-14-487)

Minuto F, Palermo C, Arvigo M \& Barreca AM 2004 The IGF system and bone. Journal of Endocrinological Investigation 28 8-10.

Mizutani A, Furukawa T, Adachi Y, Ikehara S \& Taketani S 2002 A zincfinger protein, PLAGL2, induces the expression of a proapoptotic protein Nip3, leading to cellular apoptosis. Journal of Biological Chemistry 277 15851-15858. (doi:10.1074/jbc.M111431200)

Nishimura S, Watanabe T, Mizoshita K, Tatsuda K, Fujita T, Watanabe N, Sugimoto Y \& Takasuga A 2012 Genome-wide association study identified three major QTL for carcass weight including the PLAG1CHCHD7 QTN for stature in Japanese Black cattle. BMC Genetics 1340. (doi:10.1186/1471-2156-13-40)

Okada Y, Kamatani Y, Takahashi A, Matsuda K, Hosono N, Ohmiya H, Daigo Y, Yamamoto K, Kubo M, Nakamura Y et al. 2010 A genome-wide association study in 19,633 Japanese subjects identified LHX3-QSOX2 and IGF1 as adult height loci. Human Molecular Genetics. (doi:10.1093/ hmg/ddq091)

Pallasch CP, Patz M, Park YJ, Hagist S, Eggle D, Claus R, Debey-Pascher S, Schulz A, Frenzel LP, Claasen J et al. 2009 miRNA deregulation by epigenetic silencing disrupts suppression of the oncogene PLAG1 in chronic lymphocytic leukemia. Blood 114 3255-3264. (doi:10.1182/ blood-2009-06-229898)

Pausch H, Flisikowski K, Jung S, Emmerling R, Edel C, Götz KU \& Fries R 2011 Genome-wide association study identifies two major loci affecting calving ease and growth-related traits in cattle. Genetics 187 289-297. (doi:10.1534/genetics.110.124057)

Pendeville H, Peers B, Kas K \& Voz ML 2006 Cloning and embryonic expression of zebrafish PLAG genes. Gene Expression Patterns 6 267-276. (doi:10.1016/j.modgep.2005.08.001)

Pinilla L, Aguilar E, Dieguez C, Millar RP \& Tena-Sempere M 2012 Kisspeptins and reproduction: physiological roles and regulatory mechanisms. Physiological Reviews 92 1235-1316. (doi:10.1152/physrev.00037.2010)

Pitetti JL, Calvel P, Zimmermann C, Conne B, Papaioannou MD, Aubry F, Cederroth CR, Urner F, Fumel B, Crausaz M et al. 2013 An essential role for insulin and IGF1 receptors in regulating Sertoli cell proliferation, testis size, and FSH action in mice. Molecular Endocrinolgy 27 814-827. (doi:10.1210/me.2012-1258)

Pryce JE, Hayes BJ, Bolormaa S \& Goddard ME 2011 Polymorphic regions affecting human height also control stature in cattle. Genetics 187 981-984. (doi:10.1534/genetics.110.123943) http://joe.endocrinology-journals.org

DOI: $10.1530 /$ JOE-15-0449
(C) 2016 Society for Endocrinology Printed in Great Britain 
Queimado L, Lopes C, Du F, Martins C, Bowcock AM, Soares J \& Lovett M 1999 Pleomorphic adenoma gene 1 is expressed in cultured benign and malignant salivary gland tumor cells. Laboratory Investigations $\mathbf{7 9}$ 583-589.

Reik W, Davies K, Dean W, Kelsey G \& Constância M 2001 Imprinted genes and the coordination of fetal and postnatal growth. In The Cell Cycle and Development, pp 19-31. Eds G Bock, G Cardew \& J Goode. Chichester, UK: John Wiley and Sons Ltd.

Rubin CJ, Megens HJ, Barrio AM, Maqbool K, Sayyab S, Schwochow D, Wang C, Carlborg ?, Jern P, J?rgensen CB et al. 2012 Strong signatures of selection in the domestic pig genome. PNAS 109 19529-19536. (doi:10.1073/pnas.1217149109)

Shiue Y-L, Chen L-R, Chen C-F, Chen Y-L, Ju J-P, Chao C-H, Lin Y-P, Kuo Y-M, Tang P-C \& Lee Y-P 2006 Identification of transcripts related to high egg production in the chicken hypothalamus and pituitary gland. Theriogenology 66 1274-1283. (doi:10.1016/j.theriogenology.2006.03.037)

Simpson RB, Armstrong JD, Harvey RW, Miller DC, Heimer EP \& Campbell RM 1991 Effect of active immunization against growth hormone-releasing factor on growth and onset of puberty in beef heifers. Journal of Animal Science 69 4914-4924.

Tang Q, Wu W, Xu X, Huang L, Gao Q, Chen H, Sun H, Xia Y, Sha J, Wang X et al. 2013 miR-141 contributes to fetal growth restriction by regulating PLAG1 expression. PLOS ONE 8 e58737. (doi:10.1371/journal.pone. 0058737)

Utsunomiya YT, Do Carmo AS, Carvalheiro R, Neves HH, Matos MC, Zavarez LB, P?rez O'Brien AM, S?lkner J, McEwan JC, Cole JB et al. 2013 Genome-wide association study for birth weight in Nellore cattle points to previously described orthologous genes affecting human and bovine height. BMC Genetics 14 52. (doi:10.1186/1471-2156-14-52)

Van Dyck F, Delvaux EL, Van de Ven WJM \& Chavez MV 2004 Repression of the transactivating capacity of the oncoprotein PLAG1 by SUMOylation. Journal of Biological Chemistry $27936121-36131$. (doi:10.1074/jbc.M401753200)

Van Dyck F, Declercq J, Braem CV \& Van de Ven WJM 2007a PLAG1, the protoype of the PLAG gene family: Versatility in tumour development. International Journal of Oncology 30 765-774. (doi:10.3892/ijo.30.4.765)

Van Dyck F, Braem CV, Chen Z, Declercq J, Deckers R, Kim BM, Ito S, $\mathrm{Wu} \mathrm{MK}$, Cohen DE, Dewerchin M et al. 2007b Loss of the PlagL2 transcription factor affects lacteal uptake of chylomicrons. Cell Metabolism 6 406-413. (doi:10.1016/j.cmet.2007.09.010)

Velazquez MA, Spicer LJ \& Wathes DC 2008 The role of endocrine insulinlike growth factor-I (IGF-I) in female bovine reproduction. Domestic Animal Endocrinology 35 325-342. (doi:10.1016/j.domaniend.2008.07.002)
Voz ML, Åström A-K, Kas K, Mark J, Stenman G \& Van de Ven WJM 1998 The recurrent translocation $\mathrm{t}(5 ; 8)(\mathrm{p} 13 ; \mathrm{q} 12)$ in pleomorphic adenomas results in upregulation of PLAG1 gene expression under control of the LIFR promoter. Oncogene 16 1409-1416. (doi:10.1038/sj.onc.1201660)

Voz ML, Agten NS, Van de Ven WJM \& Kas K 2000 PLAG1, the main translocation target in pleomorphic adenoma of the salivary glands, is a positive regulator of IGF-II. Cancer Research 60 106-113.

Voz ML, Mathys J, Hensen K, Pendeville H, Van Valckenborgh I, Van Huffel C, Chavez M, Van Damme B, De Moor B, Moreau Y \& Van de Ven WJM 2004 Microarray screening for target genes of the proto-oncogene PLAG1. Oncogene 23 179-191. (doi:10.1038/sj.onc.1207013)

Wibowo TA, Gaskins CT, Newberry RC, Thorgaard GH, Michal JJ \& Jiang Z 2008 Genome assembly anchored QTL map of bovine chromosome 14. International Journal of Biological Sciences 4 406-414. (doi:10.7150/ijbs.4.406)

Wilson EM \& Rotwein P 2006 Control of MyoD function during initiation of muscle differentiation by an autocrine signaling pathway activated by insulin-like growth factor-II. Journal of Biological Chemistry $\mathbf{2 8 1}$ 29962-29971. (doi:10.1074/jbc.M605445200)

Wolfe A, DiVall S \& Wu S 2014 The regulation of reproductive neuroendocrine function by insulin and insulin-like growth factor-1 (IGF-1). Frontiers in Neuroendocrinology 35 558-572. (doi:10.1016/ j.yfrne.2014.05.007)

Zatkova A, Rouillard J-M, Hartmann W, Lamb BJ, Kuick R, Eckart M, von Schweinitz D, Koch A, Fonatsch C, Pietsch T et al. 2004 Amplification and overexpression of the IGF2 regulator PLAG1 in hepatoblastoma. Genes Chromosomes and Cancer 39 126-137. (doi:10. 1002/gcc.10307)

Zheng G \& Yang YC 2005 SUMOylation and acetylation play opposite roles in the transactivation of PLAG1 and PLAGL2. Journal of Biological Chemistry 280 40773-40781. (doi:10.1074/jbc.M504334200)

Zheng J, Yu S, Jiang Z, Shi C, Li J, Du X, Wang H \& Jiang J 2014 Microarray comparison of the gene expression profiles in the adult vs. embryonic day 14 rat liver. Biomedical Reports 2 664-670. (doi:10.3892/br.2014.303)

Zhou J, Kumar TR, Matzuk MM \& Bondy C 1997 Insulin-like growth factor I regulates gonadotropin responsiveness in the murine ovary. Molecular Endocrinolgy 11 1924-1933. (doi:10.1210/mend.11.13.0032)

Zhou P, Baumgarten SC, Wu Y, Bennett J, Winston N, Hirshfeld-Cytron J \& Stocco C 2013 IGF-I signaling is essential for FSH stimulation of AKT and steroidogenic genes in granulosa cells. Molecular Endocrinolgy 27 511-523. (doi:10.1210/me.2012-1307)

Received in final form 10 November 2015

Accepted 17 November 2015

Accepted Preprint published online 17 November 2015
(C) 2016 Society for Endocrinology Printed in Great Britain 